\title{
Exploring the Effect on 5 Senses in Children under Nitrous Oxide Sedation
}

\author{
Vinita Goyel ${ }^{1}$, Aman Jain², Shivani Mathur 3 , Vinod Sachdev ${ }^{4}$, Shambhavi Singh ${ }^{5}$ \\ 1, 2,3,4,5 Department of Paediatric and Preventive Dentistry, \\ ITS Dental College Muradnagar, CDSR Ghaziabad, Uttar Pradesh, India.
}

\section{ABSTRACT}

\section{BACKGROUND}

Sensation and perception are two separate processes that are very closely related. Sensation is the input about the outside world obtained by our sensory receptors while perception is the difficult system by which the brain selects, organizes and interprets these sensations. Effects of nitrous oxide on the sensation and perception has not been unturned although role in physiological, anxiolytic, behavioural, psychomotor and analgesic parameters have been examined in both children and adults. The human senses have long been unnoticed, despite their responsiveness being of great importance. The purpose of this study was to evaluate the effectiveness of nitrous oxide inhalation sedation on 5 senses i.e. sight, hearing, touch, smell and taste at different titrations of nitrous oxide and oxygen.

\section{METHODS}

7 to 12 years old children with Frankl's behaviour rating score of 2, 3 and 4 with no prior dental experience and requiring dental treatment under nitrous oxide sedation who were systemically healthy were included in the study. The 5 senses (i.e. hearing, touch, smell, taste and vision) were evaluated with different materials at 4 different titration levels to evaluate the effect of nitrous oxide on the 5 senses T0: $100 \%$ oxygen, T1: $30 \%$ nitrous oxide, T2: $50 \%$ nitrous oxide, T3: $100 \%$ oxygen.

\section{RESULTS}

The results of the present study depicted that there is significant difference in the perception of various senses at different concentrations of nitrous oxide and also when compared to baseline values. It was observed that the patient regained the normal perception in 5 minutes after $100 \%$ oxygen post-operatively.

\section{CONCLUSIONS}

Nitrous oxide is found to depress/relax one's senses too.

\section{KEY WORDS}

Vision, Smell, Taste, Touch, Sound, Perception, Consciousness, Nitrous Oxide Sedation, Oxygen, Behaviour
Corresponding Author:

Dr Vinita Goyel,

\# 300, Ramnagar, Ghaziabad-201001,

Uttar Pradesh, India.

E-mail: vinitagoyal_mds18_21@its.edu.in

DOI: $10.14260 /$ jemds/2021/683

How to Cite This Article:

Goyel V, Jain A, Mathur S, et al. Exploring the effect on 5 senses in children under nitrous oxide sedation J Evolution Med Dent Sci 2021;10(38):3365-3369, DOI: 10.14260/jemds/2021/683

Submission 27-05-2021,

Peer Review 20-07-2021,

Acceptance 28-07-2021,

Published 20-09-2021.

Copyright (C) 2021 Vinita Goyel et al. This is an open access article distributed under Creative Commons Attribution License [Attribution 4.0 International (CC BY 4.0)] 


\section{BACKGROUND}

Since its introduction into dentistry by Horace Wells in 1844, Nitrous oxide has gained much attention in the recent past for the management of dental anxiety and pain and further to ensure that the patient is left with no unpleasant memory of the dental procedure. ${ }^{1}$ Relative analgesia, a term which was introduced by Langa (1976); as "A chemically induced altered psychological state which eliminates the fear and pain of the dental experience"; is the outcome after the treatment of child under conscious sedation. ${ }^{2}$ Quick reverse and rapid onset of analgesia make this drug popular to be used as a pharmacological behaviour management modality in paediatric dentistry. A survey reported by Wilson in 1996 of 1,758 diplomates of the American Academy of Paediatric Dentistry indicated that $89 \%$ reported the use of nitrous oxide in their practices as an adjunct to behaviour management techniques. ${ }^{3}$

Sensation and perception are two separate processes that are very closely related. Sensation is the input about the physical world obtained by our sensory receptors while perception is the complex process by which the brain selects, organizes and interprets these sensations. In other words, senses are the physiological basis of perception. Helmholtz et al. splits various experiences into two stages, with sensation representing the subjective side and perception, through cognitive processes, being the objective side. ${ }^{4}$

As a protocol, both objective signs and subjective symptoms are recorded during sedation procedure. Objective signs include the assessment of patient's face, hands, legs and feet to determine the assessment of nitrous oxide while subjective symptoms addressed the child's perception. Further, it is of paramount importance that the child regains the normal levels of consciousness, reverting to the environment around them.

Many different studies of nitrous oxide have examined the physiological, anxiolytic, behavioural, psychomotor and analgesic effects of nitrous oxide in both children and adults. Apart from these effects nitrous oxide is found to depress/relax one's senses too.

However, the response produced on various senses has not been studied and quoted in the literature to the best of author's knowledge. Hence, the present study was undertaken to evaluate the effect of nitrous oxide inhalation sedation on 5 senses i.e. sight, hearing, touch, smell, and taste at different titrations of nitrous oxide and oxygen.

The purpose of this study was to assess the effect of nitrous oxide on various senses in the same individual at different concentrations of nitrous oxide inhalation sedation.

\section{METHODS}

The present study was conducted in the Department of Paediatric and Preventive Dentistry (I.T.S. Centre for Dental Studies \& Research, Muradnagar) from January 2020 to February 2020. Ethical approval of the study was obtained from Institutional Ethical Committee. (EC clearance approval number: ITSCDSR/IIEC/RP/2019/004).
Sample size was calculated using this formula:

Sample size $=\frac{Z_{1-\alpha / 2}{ }^{2}+p(1-p)^{2}}{d^{2}}$

Here

$Z_{1-\alpha / 2}=$ Is standard normal variate [at $5 \%$ type 1 error $(\mathrm{P}<$ $0.05)$ it is 1.96 at $1 \%$ type 1 error $(\mathrm{P}<0.01)$ it is 2.58$]$. As in majority of studies, $\mathrm{P}$ values are considered significant below 0.05 , hence 1.96 is used in formula.

$\mathrm{P}=$ Expected proportion in population based on previous studies or pilot studies.

Sample Size $=\frac{(1.96)^{2} 0.8 *(1-0.8)}{(0.176)^{2}}=19.842=20$ (approximately) for each group.

Written informed consent was obtained from each subject's parents/guardians before enrolling them in the study 7 to 12 years old children with Frankl's behaviour rating score of 2, 3 and 4 with no prior dental experience and requiring dental treatment under nitrous oxide sedation who were systemically healthy (American Society of Anaesthesiologists Type I) were included in the study.

While children with Frankl's behaviour rating score of 1 having medically and developmentally compromising conditions or patients with mental/cognitive problems were excluded from the study.

The 5 senses (i.e. hearing, touch, smell, taste and vision) were evaluated at 4 different titration levels to evaluate the effect of nitrous oxide on the 5 senses.

1. T0: $100 \%$ OXYGEN

2. T1: $30 \%$ NITROUS OXIDE

3. T2: $50 \%$ NITROUS OXIDE

4. T3: $100 \%$ OXYGEN

- To check the vision of the child, four different images of concentric circles were used and the child was asked to count the circles (Figure1)

- To check the smell sensation, 4 different materials were used (jelly, talcum powder, deodorant and medicine) and the child was asked to recognise the smell (Figure1)

- To check the taste sensation, 4 different types of materials (lime juice, sugar suspension, salt suspension and topical LA) were used and the child was asked to recognise the type of taste (Figure1)

- To check the touch sensation, 4 different types of materials (sand paper, cotton, plastic spatula and cloth) were used and the child was asked to recognise the consistency of material (Figure1)

- To check the hearing sensation, beep sounds were used and the child was asked to count the total number of beeps in the audio (Figure1)

The parameters were recorded while giving 3 minutes of $100 \%$ oxygen, 3 minutes of $30 \%$ nitrous oxide, 3 minutes of $50 \%$ of nitrous oxide and post operatively after giving $100 \%$ of oxygen for 5 minutes.

The responses were recorded as "Yes" if the child was able to give the correct response and as "No" if the response given by the child was wrong. 

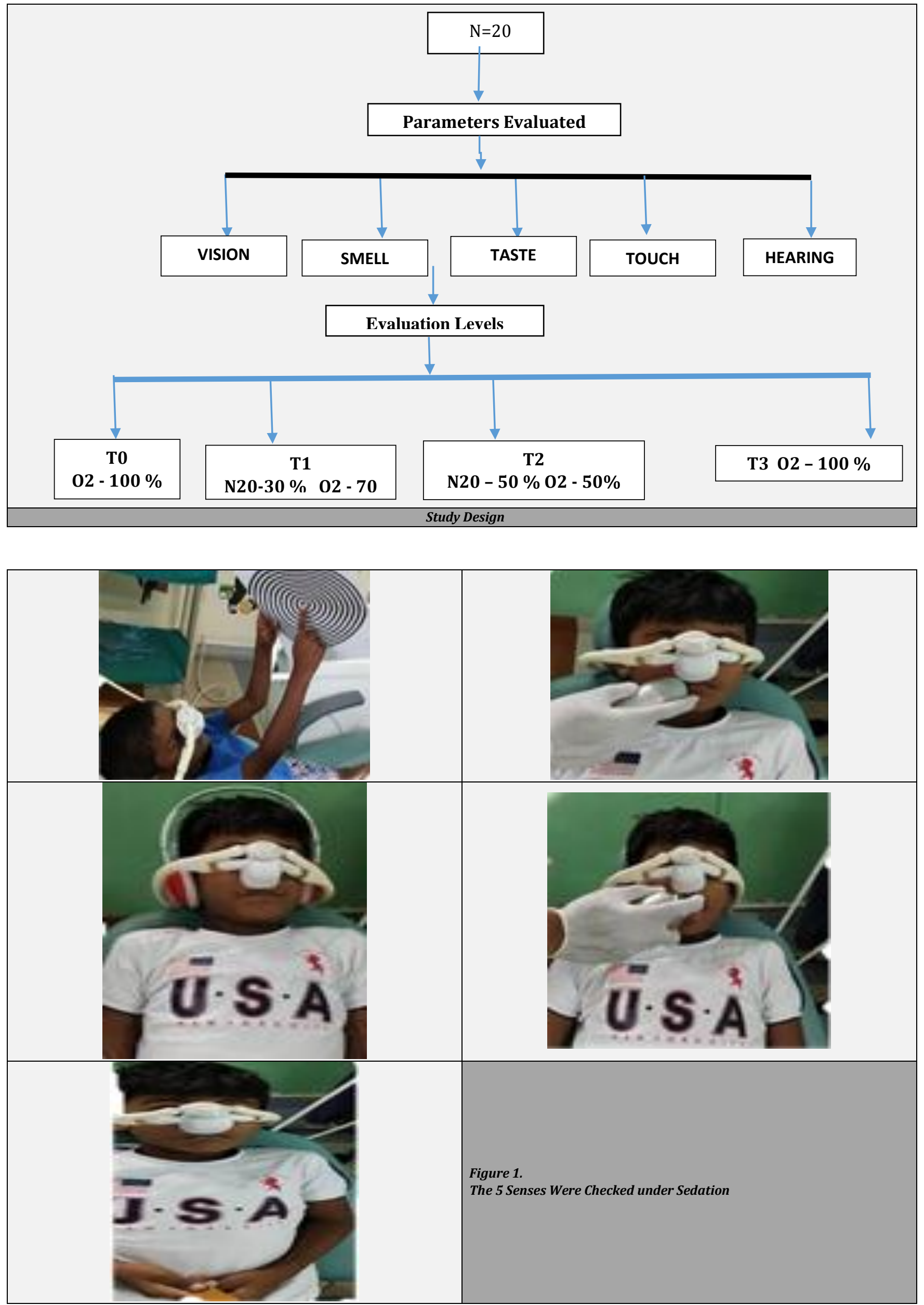


\section{Statistical Analysis}

Chi-square test was used to test the significance among the qualitative groups. Probabilities of 0.05 or less were accepted as significant. Statistical analysis was performed using Statistical Package for Social Science (SPSS Software) (IBM Corp 2013; Version 22.0; Armonk, NY). Tables are prepared by using M.S Office 2010 software.

\section{RESULTS}

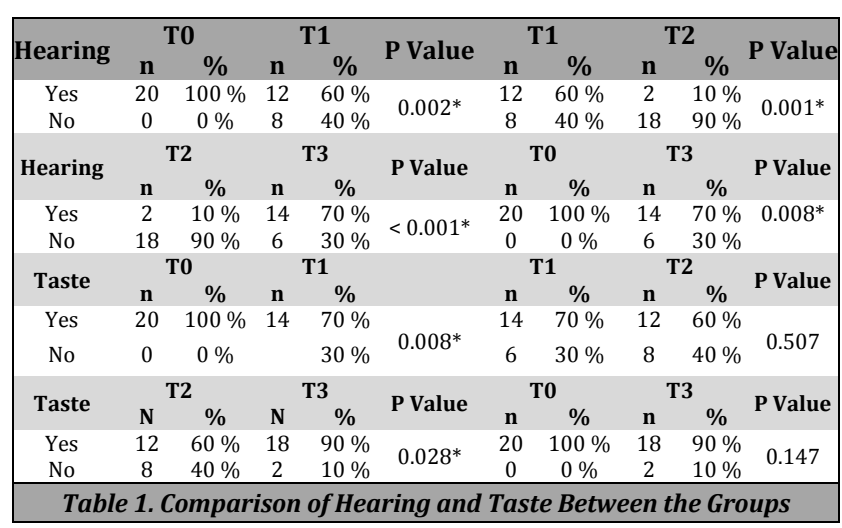

Chi-square test, * denotes test result is statistically significant at 0.05 level. The $\mathrm{P}$ value when comparing the effect of sedation on hearing was $0.002,0.001,<0.001$ and 0.008 when comparing at T0 - T1, T1 - T2, T2 - T3 and T0 - T3 respectively.

The $\mathrm{P}$ value when comparing the effect of sedation on taste was $0.008,0.507,0.028$ and 0.147 when comparing at T0 - T1, T1 - T2, T2 - T3 and T0 - T3 respectively.

\begin{tabular}{|c|c|c|c|c|c|c|c|c|c|}
\hline \multirow{2}{*}{ Touch } & \multicolumn{2}{|c|}{ T0 } & \multicolumn{2}{|c|}{ T1 } & \multirow{2}{*}{ P Value } & \multicolumn{2}{|r|}{ T1 } & \multicolumn{2}{|l|}{ T2 } \\
\hline & $\mathbf{n}$ & $\%$ & $\mathbf{n}$ & $\%$ & & $\mathbf{n}$ & $\%$ & n $\%$ & \\
\hline Yes & 20 & $100 \%$ & 12 & $60 \%$ & \multirow{2}{*}{$002^{*}$} & 12 & $60 \%$ & $40 \%$ & \multirow{2}{*}{$0.206^{*}$} \\
\hline No & 0 & $0 \%$ & 8 & $40 \%$ & & 8 & $40 \%$ & $12 \quad 60 \%$ & \\
\hline \multirow{2}{*}{ Touch } & \multicolumn{2}{|c|}{ T2 } & \multicolumn{2}{|c|}{ T3 } & \multirow{2}{*}{ P Value } & \multicolumn{2}{|r|}{ T0 } & T3 & \multirow{2}{*}{ P Value } \\
\hline & n & $\%$ & $\mathbf{n}$ & $\%$ & & $\mathbf{n}$ & $\%$ & n $\quad \%$ & \\
\hline Yes & 8 & $40 \%$ & 14 & $70 \%$ & \multirow[b]{2}{*}{0.057} & 20 & $100 \%$ & $70 \%$ & \multirow{2}{*}{$0.008^{*}$} \\
\hline No & 12 & $60 \%$ & 6 & $30 \%$ & & 0 & $0 \%$ & $30 \%$ & \\
\hline \multirow{2}{*}{ Smell } & \multicolumn{2}{|c|}{ T0 } & \multicolumn{2}{|c|}{ T1 } & \multirow{2}{*}{ P Valt } & \multicolumn{2}{|r|}{ T1 } & T2 & \multirow{2}{*}{ P Value } \\
\hline & $\mathrm{n}$ & $\%$ & $\mathrm{n}$ & $\%$ & & $\mathbf{n}$ & $\%$ & n $\quad \%$ & \\
\hline Yes & & & \multirow{2}{*}{\multicolumn{2}{|c|}{$\begin{array}{l}20 \% \\
80 \%\end{array}$}} & \multirow{2}{*}{$<0.001^{*}$} & 4 & $20 \%$ & \multirow{2}{*}{$\begin{array}{c}0 \% \\
100 \%\end{array}$} & \multirow{2}{*}{$0.035^{*}$} \\
\hline No & & & & & & 16 & $80 \%$ & & \\
\hline \multirow{2}{*}{ Smell } & \multicolumn{2}{|c|}{ T2 } & \multicolumn{2}{|c|}{ T3 } & \multirow{2}{*}{ P Value } & \multicolumn{2}{|r|}{ T0 } & T3 & \multirow{2}{*}{ P Value } \\
\hline & n & $\%$ & $\mathbf{n}$ & $\$$ & & $\mathbf{n}$ & $\%$ & n $\quad \%$ & \\
\hline Yes & 0 & $0 \%$ & 14 & $70 \%$ & & 20 & $100 \%$ & $70 \%$ & $0.00\rangle$ \\
\hline No & 20 & $100 \%$ & 6 & $30 \%$ & -0.00 & 0 & $0 \%$ & $30 \%$ & 0.000 \\
\hline & $a$ & C & & of $s$ & & $u c$ & etwe & e Groups & \\
\hline
\end{tabular}

Chi square test. * denotes test result is statistically significant at 0.05 level. The $\mathrm{P}$ value when comparing the effect of sedation on smell was $<0.001,0.035,<0.001$ and 0.008 when comparing at $\mathrm{T} 0-\mathrm{T} 1, \mathrm{~T} 1-\mathrm{T} 2, \mathrm{~T} 2-\mathrm{T} 3$ and $\mathrm{T} 0-\mathrm{T} 3$ respectively. The $\mathrm{P}$ value when comparing the effect of sedation on touch was $0.002,0.206,0.057$ and 0.008 when comparing at T0 - T1, T1 - T2, T2 - T3 and T0 - T3 respectively

\begin{tabular}{|c|c|c|c|c|c|c|c|c|c|c|}
\hline \multirow{2}{*}{ Vision } & \multicolumn{2}{|c|}{ T0 } & \multicolumn{2}{|r|}{ T1 } & \multirow{2}{*}{ P Value } & \multicolumn{2}{|r|}{ T1 } & \multicolumn{2}{|c|}{ T2 } & \multirow{2}{*}{ P Value } \\
\hline & n & $\%$ & n & $\%$ & & $\mathbf{n}$ & $\%$ & n & $\%$ & \\
\hline Yes & 20 & $100 \%$ & 0 & $0 \%$ & & 0 & $0 \%$ & 0 & $0 \%$ & \\
\hline No & 0 & $0 \%$ & 20 & $100 \%$ & & 20 & $100 \%$ & 20 & $100 \%$ & 1.000 \\
\hline \multirow{2}{*}{ Vision } & \multicolumn{2}{|c|}{ T2 } & \multicolumn{2}{|c|}{ T3 } & P Value & \multicolumn{2}{|r|}{ T0 } & \multicolumn{2}{|r|}{ T3 } & \\
\hline & $\mathbf{n}$ & $\%$ & $\mathbf{n}$ & $\%$ & Pvalue & $\mathrm{n}$ & $\%$ & $\mathbf{n}$ & $\%$ & Pvalue \\
\hline Yes & 0 & $0 \%$ & 16 & $80 \%$ & $<0.001 *$ & 20 & $100 \%$ & 16 & $80 \%$ & $0.035^{*}$ \\
\hline No & 20 & $100 \%$ & 4 & $20 \%$ & & 0 & $0 \%$ & 4 & $20 \%$ & \\
\hline \multicolumn{11}{|c|}{ Table 3. Comparison of Vision between the Groups } \\
\hline
\end{tabular}

Chi square test. * denotes test result is statistically significant at 0.05 level. The $\mathrm{P}$ value when comparing the effect of sedation on vision was $0.001,1.000,<0.001$ and 0.035 when comparing at T0 - T1, T1 - T2, T2 - T3 and T0 - T3 respectively

\section{DISCUSSION}

This study examined the effects of nitrous oxide on various senses in the same individual at different concentrations of nitrous oxide inhalation sedation. It is well documented that $\mathrm{N} 2 \mathrm{O}$ at the dosages routinely used for dental procedures affects cognitive functions such as psychomotor performances, attention, memory, reaction time, and facial recognition tasks. ${ }^{5}$

In the present study, it was observed that at $\mathrm{T}_{2}$. (50\% $\mathrm{N}_{2} \mathrm{O}$ ), eight out of twenty patients were not able to perceive the sense of taste i.e. the perception of taste may be altered by sedation. Topical local anaesthesia or any other medicament having foul taste which can cause discomfort to the patient can be masked because of the altered taste sensation in the child by the help of nitrous oxide.

The sense of sight is affected by nitrous oxide-oxygen sedation. A patient cannot detect differences in spatial position of a stimulus as readily. Peripheral vision is blurred. Occasionally a patient perceives a series of geometric figures, circles or dots. He can lose the ability to detect differences in intensity and to adjust to a large range of intensities. In the current study, it was observed that at $\mathrm{T}_{2}$. $\left(50 \% \mathrm{~N}_{2} \mathrm{O}\right)$, twelve out of twenty patients were not able to count the circles. It may be attributed to the decreased ability of eye to detect differences in the wave length composition of energy coming from a source or reflected from an object and to see these differences in range of circles. It can be beneficial to the doctor as because of the effect in the vision of the child, the focus of the child on the procedure going on him would be reduced.

The smell is the most affected sense noted in present study as at $\mathrm{T}_{2}$. (50\% $\left.\mathrm{N}_{2} \mathrm{O}\right)$, all 20 patients were not able to sense the smell. This can be beneficial as it can help mask the odour of dental chemicals such as formocresol, or the unpleasant odour caused by electrosurgery.

The sense of touch also got depressed during sedation as it was observed that at $\mathrm{T}_{2}\left(50 \% \mathrm{~N}_{2} \mathrm{O}\right)$, twelve out of twenty patients were not able to identify the objects. This depression can deeply enhance relaxation if tactile sensation is kept to a minimum. In lighter levels, this can be accomplished by having the patient uncross his arms and legs, thereby reducing pressure stimulation. Loosening of tight clothing can also be helpful. At deeper sedation levels, pain perception may even be depressed.

For child, the sense of hearing is a social sense. The sounds heard each day, in the speech of others and of caretakers, dictate much of their social behaviour. The emotions of a speaker can be revealed by the content of his speech and his voice inflection. ${ }^{6}$ In addition to simple speech, other sounds can modify the behaviour of child. In a dental office, positive vocal sedation by the dentist can help relieve fear and anxiety. Empathy and concern can positively modify a patient's reactions to stressful situations. The sense of 
hearing is the last sense to be obtunded during nitrous oxide inhalation sedation. It was noted in present study as at $\mathrm{T}_{2}$ (50 $\% \mathrm{~N}_{2} \mathrm{O}$ ), 18 out of 20 patients were not able to count the number of beep sounds. With the progressive depression of the other senses, the sense of hearing becomes progressively more acute. A patient gains in the ability to hear distant sounds clearly. Vibratory sounds are readily detected and magnified (e.g., a lab motor or an air conditioner). The dentist's voice may seem lower in magnitude and pitch and further in distance. The patient's own voice becomes slower and lower in pitch. The patient may perceive echoing of sounds.

For dental outpatients undergoing conscious sedation, recovery from sedation must be sufficient to allow a safe discharge home. As a general approach, after 10 - 15 min following the $\mathrm{N} 20 / 02$ sedation, the patient is usually fit to be discharged. Ayer and Getter reported that psychomotor impairment occurring from the use of $\mathrm{N}_{2} \mathrm{O}$ (range from $35 \%$ to $40 \%$ ) during dental treatment was completely recovered after $20 \mathrm{~min}$.

Thompson et al. reported that $25 \%$ nitrous oxide impairs higher cognitive tasks and thus patients can resume normal activities in the post-operative period and so there is need for an escort to accompany them. ${ }^{\text {? }}$

The results of the present study depicted that there is significant difference in the perception of various senses at different concentrations of nitrous oxide and also when compared to baseline values. Also, it was observed that the patient regained the normal perception 5 minutes after 100 $\%$ oxygen post-operatively.

\section{CONCLUSIONS}

- Though various physiological and psychological effects of nitrous oxide have been studied by various authors, literature is still deficient pertaining to its effect on various senses and hence the present study was undertaken.
- The results of the study proved that patient must not be left unattended post sedation for a minimum of 5 minutes to even 20 minutes in few cases.

- The results further conclude that there is a definitive effect of inhalation sedation on the senses and perception of the patient receiving stimulus.

Data sharing statement provided by the authors is available with the full text of this article at jemds.com.

Financial or other competing interests: None.

Disclosure forms provided by the authors are available with the full text of this article at jemds.com.

\section{REFERENCES}

[1] Onody P, Gil P, Hennequin M. Safety of inhalation of a 50 $\%$ nitrous oxide / oxygen premix: a prospective survey of 35828 administrations. Drug Saf 2006;29(7):633-40.

[2] Langa H. Relative analgesia in dental practice: inhalation analgesia and sedation with Nitrous Oxide Oxygen. Philadelphia: WB Saunders Co, 1976.

[3] Wilson S. A survey of the American Academy of Pediatric Dentistry membership: nitrous oxide and sedation. Pediatr Dent 1996;18(4):287-93.

[4] Gilchrist A. Objective and subjective sides of perception. In: Hatfield G, Allred S, eds. Visual experience: sensation, cognition and constancy. Oxford University Press 2012: p. 105-21.

[5] Craig DC, Wildsmith JAW, Royal College of Anaesthetists, et al. Conscious sedation for dentistry: an update. $\mathrm{Br}$ Dent J 2007;203(11):629-31.

[6] Chermak GD, Hall JW 3rd, Musiek FE. Differential diagnosis and management of central auditory processing disorder and attention deficit hyperactivity disorder. Journal of the American Academy of Audiology 1999;10(6):289-303.

[7] Thompson JM, Neave N, Moss MC, et al. Cognitive properties of sedation agents: comparison of the effects of nitrous oxide and midazolam on memory and mood. Br Dent J 1999;187:557-62. 